Technological University Dublin

DÜBLIN

ARROW@TU Dublin

\title{
Investigation of the Stereoselective Synthesis of the Indane Dimer PH46A, a New Potential Anti-inflammatory Agent
}

\author{
Graham R. Cumming \\ Celtic Catalysts Ltd, Ireland \\ Tao Zhang \\ Technological University Dublin, tao.zhang@tudublin.ie \\ Gaia Scalabrino \\ Trino Therapeutics Ltd, Ireland
}

See next page for additional authors

Follow this and additional works at: https://arrow.tudublin.ie/schfsehart

Part of the Life Sciences Commons

\section{Recommended Citation \\ Cumming, G., Zhang, T., Scalabrino, G., Frankish, N. and Sheridan, H. (2017). Investigation of the Stereoselective Synthesis of the Indane Dimer PH46A, a New Potential Anti-inflammatory Agent. Journal of Organic Process Research \& Development 21, pp.1972-1979. doi:10.1021/acs.oprd.7b00258}

This Article is brought to you for free and open access by the School of Food Science and Environmental Health at ARROW@TU Dublin. It has been accepted for inclusion in Articles by an authorized administrator of ARROW@TU

Dublin. For more information, please contact

arrow.admin@tudublin.ie, aisling.coyne@tudublin.ie, gerard.connolly@tudublin.ie.

Funder: The Wellcome Trust UK, Enterprise Ireland

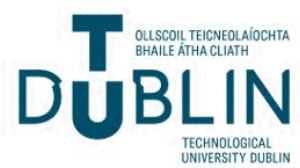


Authors

Graham R. Cumming, Tao Zhang, Gaia Scalabrino, Neil Frankish, and Helen Sheridan

This article is available at ARROW@TU Dublin: https://arrow.tudublin.ie/schfsehart/348 


\title{
Investigation of the Stereoselective Synthesis of the Indane Dimer PH46A, a New Potential Anti-inflammatory Agent
}

\author{
Graham R. Cumming, ${ }^{\dagger, \|}$ Tao Zhang, ${ }^{\ddagger}, \|_{\odot}$ Gaia Scalabrino, ${ }^{\ddagger}, \|$ Neil Frankish, ${ }^{\ddagger, \S}$ and Helen Sheridan*, ${ }^{*, \S}$ \\ ${ }^{\dagger}$ Celtic Catalysts Ltd, NovaUCD, Belfield, Dublin 4, Ireland \\ ${ }^{\ddagger}$ Trino Therapeutics Ltd, The Tower, Trinity Technology \& Enterprise Campus, Dublin 2, Ireland \\ ${ }^{\S}$ Drug Discovery Group, School of Pharmacy and Pharmaceutical Sciences \& Trinity Biomedical Sciences Institute (TBSI), Trinity \\ College, Dublin 2, Ireland
}

Supporting Information

ABSTRACT: PH46A, belonging to a class of 1,2-Indane dimers, has been developed by our research group as a potential therapeutic agent for the treatment of inflammatory and autoimmune diseases. The initial synthetic route to PH46A gave a low overall yield, due in large part to the generation of undesired diastereoisomer 5 and the unwanted enantiomer $(R, R)-8$ during the synthesis. The aim of this work was to carry out a comprehensive investigation into the stereoselective synthesis of PH46A. Significant progress was made on the ketone reduction step, where the use of triisobutylaluminum $\left[\mathrm{TiBA}, \mathrm{Al}(\mathrm{iBu})_{3}\right]$ afforded high selectivity for the target diastereoisomer $(\mathrm{rac})-6$, compared to the unfavorable ratio obtained using a previous process. This enabled a multikilo scale synthesis of PH46A in a GMP environment. Further, a brief proof-of-principle investigation was carried out using an achiral phase transfer catalyst (PTC) for alkylation at the methine carbon of the parent indanone.

\section{INTRODUCTION}

The new chiral chemical entity PH46A, 6-(methylamino)hexane-1,2,3,4,5-pentanol 4-(((1S,2S)-1-hydroxy-2,3-dihydro$1 H, 1^{\prime} H$-[2,2-biinden]-2-yl)methyl)benzoate, was previously synthesized by our research group ${ }^{1}$ and shown to have potential therapeutic activity in the areas of inflammation and autoimmune diseases, including inflammatory bowel disease. ${ }^{2}$ PH46A recently completed a first-in-man Phase I clinical trial study. ${ }^{3}$ The original synthetic route to this "first-in-class" molecule included conventional organic chemistry and preparative chiral HPLC separation (Scheme 1a). ${ }^{2}$

The overall yield of the original route (Scheme 1a) was less than satisfactory, due to the generation of the undesired diastereoisomer $(\mathrm{rac})-\mathbf{5}$ and the unwanted enantiomer $(R, R)-\mathbf{8}$. The reduction of ketone 3 (step 3 ) was carried out using sodium borohydride $\left(\mathrm{NaBH}_{4}\right)$, which afforded a 60:40 ratio of the unwanted diastereoisomer ( $\mathrm{rac}$ ) 5 and desired diastereoisomer ( $\mathrm{rac})-6 .{ }^{2}$ Bulkier reagents, such as L-Selectride, gave even greater selectivity for the undesired isomer, while conceptually different reductants, such as DIP-chloride and CBS reagent, gave poor conversion. ${ }^{4}$ The separation of diastereoisomers $\mathbf{5}$ and $\mathbf{6}$ also proved challenging, especially on larger scales, due to their similar chemical and physical properties. Therefore, the development of a scalable stereoselective route for the synthesis of $\mathrm{PH} 46 \mathrm{~A}$ was desirable to eliminate or reduce the cost burdens of generating the undesired diastereoisomer and of carrying out a large scale separation of the enantiomers. The current article describes our initial work toward this goal, which underpinned the kilo-scale GMP manufacture of PH46A. Further exploration is ongoing to optimize the synthesis, and it is anticipated that a combination of enantioselective alkylation to afford ketone 4 as a single enantiomer and subsequent substrate-controlled diastereose- lective reduction will ultimately lead to a highly stereoselective synthesis of PH46A (Scheme 1b).

Our initial efforts were directed toward optimization of the diastereoselectivity in step 3 (Scheme 1a), as even moderate improvements could have immediate impact upon yields and purification in planned scale-up work. Prior work had shown $\mathrm{NaBH}_{4}$ in methyl tert-butyl ether (MTBE) to be unreactive, probably due to the extremely low solubility of this reagent in simple ethers solvents. $\mathrm{NaBH}_{4}$ in diglyme and $\mathrm{LiBH}_{4}$ in diethyl ether, tetrahydrofuran (THF), and diglyme combinations were briefly explored in this study, without leading to any significant improvements. Meerwein-Ponndorf-Verley-Oppenauer (MPVO) reduction and equilibration systems were also investigated. Initial trial using aluminum(III) isopropoxide $\left(\mathrm{Al}(\mathrm{OiPr})_{3}\right)$ gave high selectivity in some cases; however, the high dilution required and low reaction rate left a scalable process out of reach. The use of neodymium(III) isopropoxide $\left(\mathrm{Nd}(\mathrm{O} i \mathrm{Pr})_{3}\right)$ along with a simple zeolite catalyst has been reported to promote the racemization of chiral alcohols. ${ }^{5}$ When applied to our system, a thermodynamic product distribution was targeted as a result, in contrast to the kinetic product mixture expected from metal borohydride reduction; however, results were disappointing. Finally, a scalable, selective process was developed using triisobutylaluminum, [TiBA, $\left.\left(\mathrm{Al}(i \mathrm{Bu})_{3}\right)\right]$, a reagent not often encountered as a carbonyl reducing agent.

The second part of this study comprised a brief investigation of achiral phase transfer catalyst (PTC)-promoted benzylation of ketone 3, to support future development of the enantioselective variant, which had been identified as a particularly interesting avenue of research. ${ }^{6}$ Unlike the use of a chiral amide base, such PTC reactions are catalytic in the

Received: July 29, 2017

Published: November 27, 2017 
Scheme 1. (a) Original Synthetic Route to PH46A with Key Intermediates Generated from Steps 3 and 5; (b) Proposed Stereoselective Synthesis of the Desired Isomer $(S, S)-6$
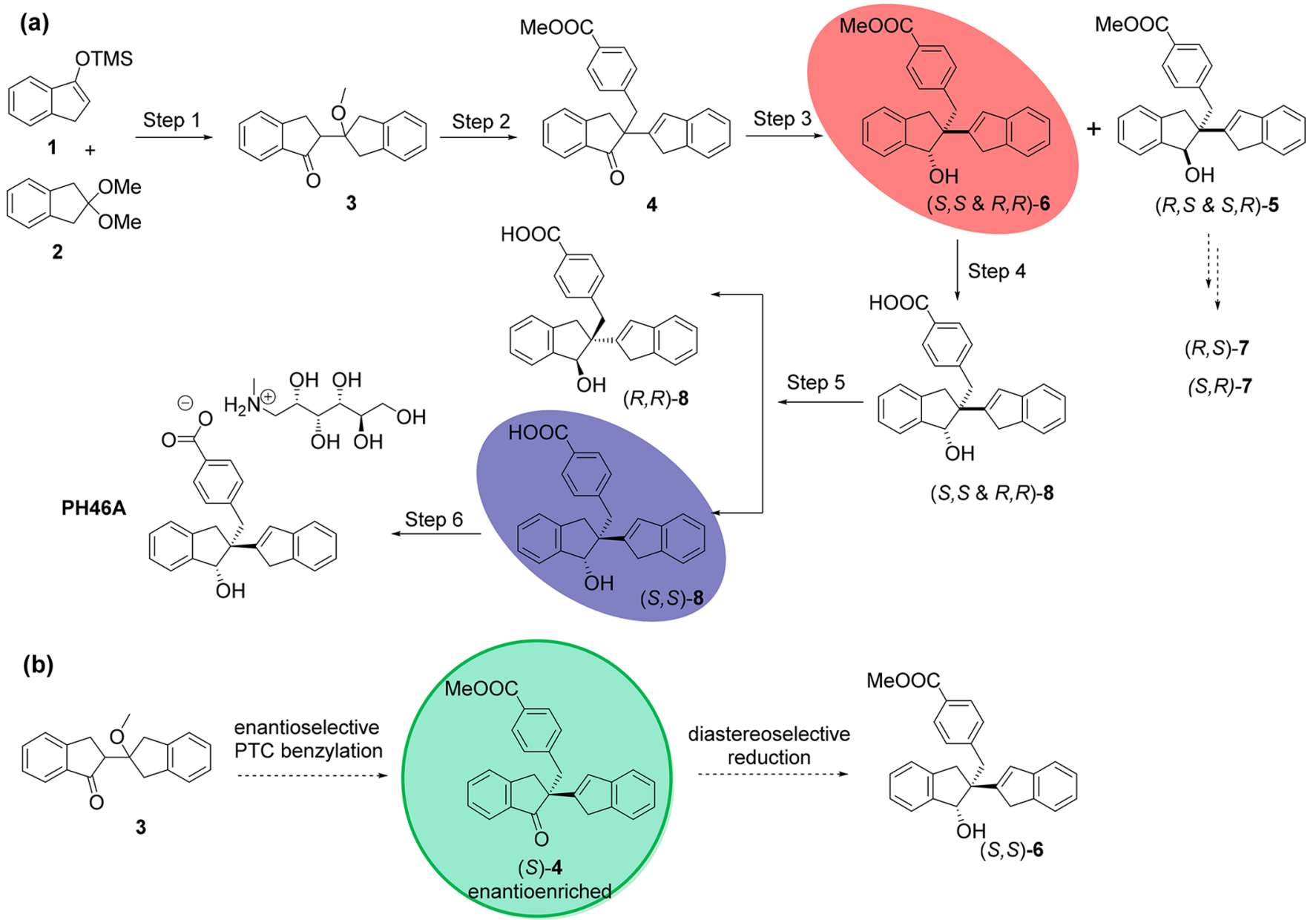

Scheme 2. Reduction of Ketone 4

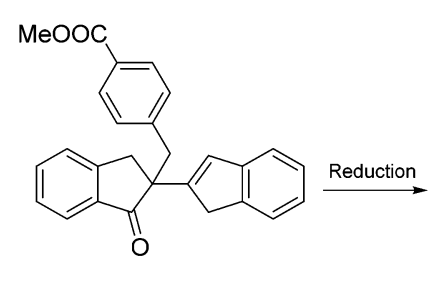

4

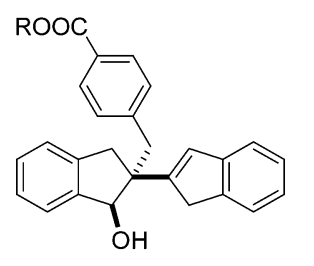

Diastereomer D1 $5(\mathrm{R}=\mathrm{Me})$

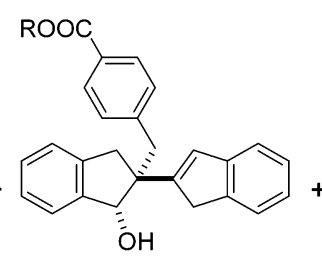

Diastereomer D2 $6(\mathrm{R}=\mathrm{Me})$

$10(\mathrm{R}=\mathrm{iPr})$

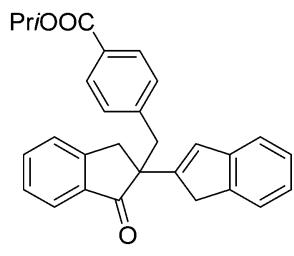

11 source of chiral information and typically do not require the exclusion of air or moisture. ${ }^{7}$

\section{RESULTS AND DISCUSSION}

The absolute stereochemistry of PH46 (parent compound of PH46A) had previously been established as an $S$ configuration at both C-1 and C-2. ${ }^{1}$ This configuration was shown to be fundamental to the potent anti-inflammatory effects of the molecule. ${ }^{2}$ For simplicity and clarity, the descriptors D1 (with nontarget configuration, $S, R$ and $R, S$ ) and $\mathrm{D} 2$ (with target configuration, $S, S$ and $R, R$ ) are used throughout the discussion for the Me-, isopropyl (iPr)-, and tert-butyl ( $t \mathrm{Bu})$-ester derivatives of hydroxyl acids 7 and 8 . Reference standards for all isomers were prepared independently to avoid ambiguity in analyses. Experimental procedures and analytical data are given in the Supporting Information (Figures S1 and S2).

Diastereoselective Reduction. Benchmark Reaction Using $\mathrm{NaBH}_{4}$ in $\mathrm{MeOH}$. A standard reduction of ketone (rac)-4 was first carried out on a $5 \mathrm{~g}$ scale, using conditions previously described. ${ }^{2}$ The reaction was complete in under $2 \mathrm{~h}$, resulting in the expected 3:2 diastereoisomeric mixture of D1 (5) and D2 (6) (Scheme 2 and Supporting Information Figures S3 and S4).

Reduction with $\mathrm{NaBH}_{4}$ in Isopropanol (IPA) or Diglyme. As noted in the introduction, previous work in our group had shown that bulky reducing agents increased selectivity toward the unwanted diastereoisomer $\mathbf{5}$. We considered that the poor selectivity observed in reduction of ketone 4 using $\mathrm{NaBH}_{4} /$ $\mathrm{MeOH}$ might be attributable in part to rapid reaction of $\mathrm{NaBH}_{4}$ 
with $\mathrm{MeOH}$ to form various reductants of the general formula $\mathrm{H}_{n} \mathrm{~B}(\mathrm{OMe})_{(4-n)},{ }^{8}$ in which one or more of the hydrides present may be reactive, each potentially with differing selectivity as a function of steric and electronic changes. Therefore, the effect of a smaller reductant was explored, beginning with unmodified $\mathrm{NaBH}_{4}$ in IPA (Table 1), a solvent which is largely unreactive

\section{Table 1. Reductions of Ketone 4 Using $\mathrm{NaBH}_{4}$ in IPA ${ }^{a}$}

\begin{tabular}{ccccc} 
& & \multicolumn{3}{c}{$\mathrm{D} 1 / \mathrm{D} 2$ ratio (area\% conversion) } \\
\cline { 3 - 5 } entry & conditions & $16 \mathrm{~h} / \mathrm{rt}^{b}$ & $+4 \mathrm{~h} / 50{ }^{\circ} \mathrm{C}^{c}$ & $+28 \mathrm{~h} / 50{ }^{\circ} \mathrm{C}^{c}$ \\
1A & 0.25 equiv of $\mathrm{NaBH}_{4}$ & $50: 50(2 \%)$ & $50: 50(10 \%)$ & $47: 53(47 \%)$ \\
1B & 0.5 equiv of $\mathrm{NaBH}_{4}$ & $48: 52(3 \%)$ & $49: 51(17 \%)$ & $42: 58(95 \%)$ \\
1C & 1.0 equiv of $\mathrm{NaBH}_{4}$ & $46: 54(3 \%)$ & $48: 52(34 \%)$ & $42: 58(>99 \%)^{d}$ \\
1D & 2.0 equiv of $\mathrm{NaBH}_{4}$ & $44: 55(6 \%)$ & $48: 52(62 \%)$ & $31: 69(>99 \%)^{d}$
\end{tabular}

${ }^{a}$ Conditions: IPA $(100 \mathrm{~mL} / \mathrm{g}) .{ }^{b}$ Ratios measured from Me-ester peaks by HPLC. ${ }^{c}$ Ratios measured from $i$ Pr-ester peaks by HPLC. ${ }^{d}$ Accompanied by significant hydrolysis to 7 and 8 and other byproducts.

toward this reducing agent. ${ }^{9}$ However, all reactions were extremely slow at $\mathrm{rt}$ and at $50{ }^{\circ} \mathrm{C}$. In all cases, the initial diastereoisomeric ratio (d.r.) $\mathrm{D} 1 / \mathrm{D} 2$ (at rt or $50{ }^{\circ} \mathrm{C}$ ) was approximately $1: 1$. In addition, an extra set of peaks with longer retention times (reversed phase HPLC) and with ratios roughly corresponding to those of the starting material and expected products was observed. These were identified as iPr-esters 9, 10, and 11; data for these products are given in the Supporting Information (Scheme S1, Figures S5 and S6). As the transesterification increased as a function of borohydride stoichiometry, it appears that the process was promoted by a boron-containing species. On extended heating ( $28 \mathrm{~h})$, some changes to d.r. were observed, with the desired isomer 6 being predominant (D1/D2 up to 30:70) in entries $1 \mathrm{C}$ and $1 \mathrm{D}$. However, this was accompanied by increased levels of byproduct formation (including some hydrolysis to the acids) and it was not possible to determine whether this was a genuine change in selectivity or the result of side reactions preferentially removing diastereoisomer D1. Interestingly, at least two of the hydrides of $\mathrm{NaBH}_{4}$ seemed to be active, given the conversions in entries $1 \mathrm{~A}$ and $1 \mathrm{~B}$.

Subsequent reactions were carried out in diglyme, chosen as an aprotic solvent in which both $\mathrm{NaBH}_{4}$ and $\mathrm{LiBH}_{4}$ are soluble. A pair of reactions (Table 2, entries $2 \mathrm{~A}$ and $2 \mathrm{~B}$ ) were carried out using $\mathrm{NaBH}_{4}$, both with and without TEA (1 equiv), which has been reported ${ }^{4}$ to enhance reactivity. The reactions were

Table 2. Reductions of Ketone 4 Using $\mathrm{NaBH}_{4}$ and $\mathrm{LiBH}_{4}$ in Diglyme $^{a}$

\begin{tabular}{|c|c|c|c|c|}
\hline \multirow[b]{2}{*}{ entry } & \multirow[b]{2}{*}{ conditions } & \multicolumn{3}{|c|}{ D1/D2 ratio (area\% conversion) } \\
\hline & & $3 \mathrm{~h} / \mathrm{rt}^{b}$ & overnight $/ \mathrm{rt}^{b}$ & $+8 \mathrm{~h} / 90^{\circ} \mathrm{C}^{b, c}$ \\
\hline $2 \mathrm{~A}$ & 1 equiv of $\mathrm{NaBH}_{4}$ & $58: 42(8 \%)$ & $56: 44(12 \%)$ & $46: 54(85 \%)$ \\
\hline $2 \mathrm{~B}$ & $\begin{array}{l}1 \text { equiv of } \mathrm{NaBH}_{4} / \\
\text { TEA }\end{array}$ & $60: 40(5 \%)$ & $56: 44(6 \%)$ & $48: 52(>99 \%)$ \\
\hline $2 \mathrm{C}$ & 0.25 equiv of $\mathrm{LiBH}_{4}$ & $\begin{array}{r}63: 37 \\
\quad(18 \%)\end{array}$ & $60: 40(31 \%)$ & $54: 46(92 \%)$ \\
\hline $2 \mathrm{D}$ & 0.5 equiv of $\mathrm{LiBH}_{4}$ & $\begin{array}{l}61: 39 \\
(23 \%)\end{array}$ & $58: 42(49 \%)$ & $50: 50(97 \%)$ \\
\hline $2 \mathrm{E}$ & 1.0 equiv of $\mathrm{LiBH}_{4}$ & $\begin{array}{l}60: 40 \\
(33 \%)\end{array}$ & $56: 44(79 \%)$ & $51: 49(>99 \%)$ \\
\hline
\end{tabular}

${ }^{a}$ Conditions: Diglyme $(100 \mathrm{~mL} / \mathrm{g}) .{ }^{b}$ Ratios measured from Me-ester peaks by HPLC. ${ }^{c}$ Reduced accuracy due to byproduct formation. rather slow at rt and showed similar selectivity (at low conversion) to the $\mathrm{NaBH}_{4} / \mathrm{MeOH}$ system. Higher conversation on heating was observed, but was accompanied by some degradation. TEA had no significant effect in our system.

Reductions Using $\mathrm{LiBH}_{4} \cdot \mathrm{LiBH}_{4}$ is often more versatile than $\mathrm{NaBH}_{4}$ in reductions, as it is soluble in a greater range of aprotic solvents, such as THF, diethyl ether, MTBE, and diglyme. After an initial test with a large excess (5 equiv) of $\mathrm{LiBH}_{4}$ in THF at rt overnight demonstrated that the ester was resistant to reduction, a set of reactions in diglyme were carried out (Table 2, entries 2C-2E) to allow direct comparison with $\mathrm{NaBH}_{4}$. The results showed selectivity similar to that of $\mathrm{NaBH}_{4}$ in diglyme, but with higher reactivity. Given time, all the hydrides of $\mathrm{LiBH}_{4}$ reacted, but no useful selectivity was achieved under these conditions.

Meerwein-Ponndorf-Verley-Oppenauer (MPVO) System. The Meerwein-Ponndorf-Verley-Oppenauer reduction is quite different from reductions using borohydride reagents. First, the reaction is, in principle, entirely reversible. ${ }^{10}$ Second, the steric requirements of the transition state can be quite distinct from those of other hydride donors, as the MPVO system has a six-membered transition state in which the carbonyl group is coordinated to the metal of the reagent. The reagent, usually $\mathrm{Al}(\mathrm{O} i \mathrm{Pr})_{3}{ }^{11}$ or a lanthanide(III) isopropoxide, $^{12}$ is theoretically catalytic, but in the case of $\mathrm{Al}(\mathrm{O} i \mathrm{Pr})_{3}$ larger amounts ( $>1$ equiv) are usually necessary for acceptable rates. Initially, investigations of this system and variants were planned with the aim of obtaining the thermodynamic product rather than the kinetic product as expected from the use of $\mathrm{NaBH}_{4}$ or other irreversible reducing agents. However, while the reaction is reversible in principle, the equilibrium position may not be reached due to other factors and so identification of a thermodynamic product distribution is not trivial.

MPVO reductions with IPA as both solvent and hydride donor are common, with the equilibrium being driven by the vast excess of the alcohol present. ${ }^{13}$ Alternatively, toluene is often used as the main solvent with a smaller excess of IPA. In this case the equilibrium can be driven by loss of acetone to the vapor phase at elevated temperature. ${ }^{14} \mathrm{Al}(\mathrm{O} i \mathrm{Pr})_{3}$-promoted MPVO reductions were first examined at $\mathrm{rt}$ and $75^{\circ} \mathrm{C}$ (entries $3 \mathrm{~A}-\mathrm{D}$, Table 3), using bulk-grade IPA as hydride donor. Reactions were carried out below the reflux temperature for either IPA or toluene, under which conditions acetone removal would not have been efficient. As with reactions of $\mathrm{NaBH}_{4}$ in IPA, these were accompanied by a high level of transesterification to the $i$ Pr-esters. Although conversions were low, entries $3 \mathrm{~B}$ and $3 \mathrm{C}$ showed a surprising degree of selectivity for the desired diastereoisomer, with a ratio of approximately 5:95 in favor of D2 (6 or 10) in each case. No further change was observed on extended heating. Investigation showed that the IPA used had a water content of $>200 \mu \mathrm{g} / \mathrm{mL}$, which at the high dilutions used could well have resulted in reagent degradation.

Further experiments were carried out (entries 4A-C, Table 3) using fresh HPLC-grade IPA with a water content $<70 \mu \mathrm{g} /$ $\mathrm{mL}$. As temperature and dilution were increased for this set of reactions, direct comparisons could not be made, but the effect on conversion appeared to be dramatic (compare entries 4A and $3 \mathrm{~B}$ ). In entry $4 \mathrm{~B}$, where a larger excess of reagent was used, conversion reached $90 \%$ HPLC area after overnight heating. Use of substoichiometric $\mathrm{Nd}(\mathrm{O} i \mathrm{Pr})_{3}$ (entry 4C) was not effective; stoichiometric use was not considered for cost reasons. Entries 5 and $6 \mathrm{~A}-6 \mathrm{C}$ were conducted in an effort to 
Table 3. Reductions of Ketone 4 Using $\mathrm{Al}(\mathrm{OiPr})_{3}$ (Entries 3-6) and MPVO-Scrambling of Mixture 5/6 Using $\mathrm{Nd}(\mathrm{OiPr})_{3}$ $(\text { Entry } 7)^{a}$

\begin{tabular}{|c|c|c|c|c|c|}
\hline \multirow[b]{2}{*}{ entry } & \multirow[b]{2}{*}{ conditions } & \multicolumn{4}{|c|}{$\mathrm{D} 1 / \mathrm{D} 2$ ratio (area\% conversion) } \\
\hline & & $2 \mathrm{~h}$ & $5.5 \mathrm{~h}$ & $16 \mathrm{~h}$ & $22 \mathrm{~h}$ \\
\hline $3 \mathrm{~A}$ & 2 equiv of $\mathrm{Al}(\mathrm{O} i \mathrm{Pr})_{3}$, IPA $(100 \mathrm{~mL} / \mathrm{g})$, rt & n.r. & n.r. & n.r. & n.r. \\
\hline $3 \mathrm{~B}$ & 2 equiv of $\mathrm{Al}(\mathrm{O} i \mathrm{Pr})_{3}, \mathrm{IPA}(100 \mathrm{~mL} / \mathrm{g}), 75^{\circ} \mathrm{C}$ & - & - & $5: 95(28 \%)^{c}$ & n.c. \\
\hline $3 \mathrm{C}$ & 2 equiv of $\mathrm{Al}(\mathrm{OiPr})_{3}$, IPA ( 5 equiv), TOL $(100 \mathrm{~mL} / \mathrm{g}), 75^{\circ} \mathrm{C}$ & - & - & $6: 94(7 \%)^{b}$ & n.c. \\
\hline $3 \mathrm{D}$ & 2 equiv of $\mathrm{Al}(\mathrm{O} i \mathrm{Pr})_{3}$, TFA ( 2 equiv), IPA ( 5 equiv $)$, TOL $(100 \mathrm{~mL} / \mathrm{g})$, rt & $(<2 \%)$ & - & - & n.c. \\
\hline $4 \mathrm{~A}$ & 2 equiv of $\mathrm{Al}(\mathrm{O} i \mathrm{Pr})_{3}$, IPA $(150 \mathrm{~mL} / \mathrm{g}), 95^{\circ} \mathrm{C}$ (reflux) & $5: 95(21 \%)^{c}$ & $5: 95(47 \%)^{c}$ & - & $5: 95(84 \%)^{c}$ \\
\hline $4 \mathrm{~B}$ & 4 equiv of $\mathrm{Al}(\mathrm{O} i \mathrm{Pr})_{3}$, IPA $(150 \mathrm{~mL} / \mathrm{g}), 95{ }^{\circ} \mathrm{C}$ (reflux) & $5: 95(44 \%)^{c}$ & $5: 95(76 \%)^{c}$ & - & $6: 94(90 \%)^{c}$ \\
\hline $4 \mathrm{C}$ & 0.2 equiv of $\mathrm{Nd}(\mathrm{O} i \mathrm{Pr})_{3}$, IPA $(150 \mathrm{~mL} / \mathrm{g}), 95{ }^{\circ} \mathrm{C}$ (reflux) & $20: 80(<2 \%)^{b}$ & $20: 80(2 \%)^{b}$ & - & $(12 \%)^{c} 23: 77$ \\
\hline 5 & 2 equiv of $\mathrm{Al}(\mathrm{OiPr})_{3}$, IPA $(10 \mathrm{~mL} / \mathrm{g}), 110^{\circ} \mathrm{C}$ (reflux) & $12: 88(26 \%)^{c}$ & $13: 87(42 \%)^{c}$ & - & $23: 77(53 \%)^{c}$ \\
\hline $6 \mathrm{~A}$ & 4 equiv of $\mathrm{Al}(\mathrm{O} i \mathrm{Pr})_{3}$, IPA $(20 \mathrm{~mL} / \mathrm{g}), 95{ }^{\circ} \mathrm{C}$ (reflux) & - & - & - & $20: 80(75 \%)^{c}$ \\
\hline $6 \mathrm{~B}$ & 4 equiv of $\mathrm{Al}(\mathrm{O} i \mathrm{Pr})_{3}$, IPA $(50 \mathrm{~mL} / \mathrm{g}), 95{ }^{\circ} \mathrm{C}$ (reflux) & - & - & - & $11: 89(87 \%)^{c}$ \\
\hline $6 \mathrm{C}$ & 4 equiv of $\mathrm{Al}(\mathrm{OiPr})_{3}$, IPA $(200 \mathrm{~mL} / \mathrm{g}), 95^{\circ} \mathrm{C}$ (reflux) & - & - & - & $5: 95(83 \%)^{c}$ \\
\hline 7 & $\mathrm{Nd}(\mathrm{O} i \mathrm{Pr})_{3}(0.2$ equiv $)$, acetone $(0.5$ equiv $), \mathrm{TOL}, 50{ }^{\circ} \mathrm{C}$ & $89: 11$ & - & - & - \\
\hline
\end{tabular}

${ }^{a}$ Conditions: see table. ${ }^{b}$ Ratio measured from Me ester peaks at low conversion. ${ }^{c}$ Ratio measured from $i$ Pr-ester peaks at low conversion; TOL $=$ toluene; n.r. $=$ no reaction; n.c. $=$ no change; $(-)=$ not determined. Scale: $1 \mathrm{mmol}$ ketone 4 except for entry $5(10 \mathrm{mmol})$.

Scheme 3. MPVO Scrambling of Diastereoisomer Mixture 5/6 Using a Neodymium(III) Catalyst

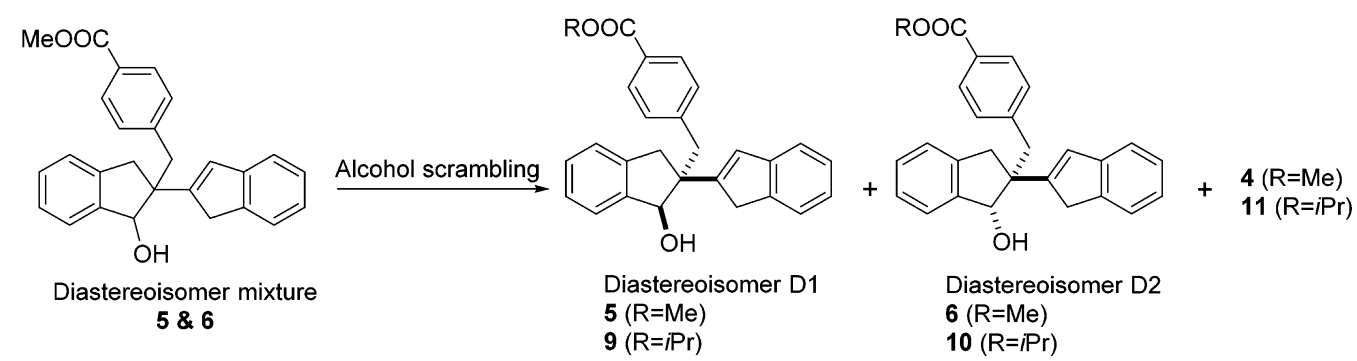

maximize conversion and improve the practicality of the process. A reaction (entry 5) was carried out at $10 \mathrm{mmol}$ scale with greatly increased concentration $(10 \mathrm{~mL} / \mathrm{g})$, which was expected to avoid significant hydrolysis of the reagent by water in the solvent. The temperature was also raised (made possible by the higher reflux temperature of the more concentrated mixture) to favor conversion by driving off the acetone produced. However, conversion after overnight heating was poor and the D1/D2 ratio was significantly worse than that seen on smaller scales under more dilute conditions. Further investigation on smaller scale (entries 6A-C, Table 3) was conducted to determine whether this was a temperature or concentration effect, with a high loading of reagent used to favor the conversion, as in entry $4 \mathrm{~B}$. The results showed clearly that increasing concentration led to poorer D1/D2 ratios, as well as reduced conversion. We surmised that the increased concentration favored the reverse reaction as a result of higher acetone concentration, leading to both lower conversion and more opportunity for equilibration of reaction products. Though the hypothesis of a tendency toward an equilibrium position was supported by the slow erosion of the $\mathrm{D} 1 / \mathrm{D} 2$ ratio with time in reaction entry 5 , it is still possible that the observed effect was simply due to changes to the nature (e.g., polarity and solvation) of the reaction environment.

To help understand the MPVO system further, scrambling of a diastereoisomeric mixture of 5 and 6 (d.r. 60:40) using catalytic $\mathrm{Nd}(\mathrm{O} i \mathrm{Pr})_{3}$ was investigated, with the aim of forming the thermodynamic product by concurrent oxidation and reduction (Scheme 3 and entry 7 in Table 3). A relatively high loading of acetone ( 0.5 equiv) was used as the redox partner to accelerate the reaction. To our surprise, along with the expected formation of ketone 4, the undesired isomer 5 prevailed (D1/ D2, 89:11) after a relatively short reaction time $(2.5 \mathrm{~h})$. While this suggests that diastereoisomer D1 is the thermodynamic product, from this experiment alone we cannot rule out a selective oxidation of the diastereoisomer D2. To our knowledge, the relevant literature discusses this type of reaction only in terms of racemization of a single stereocenter or scrambling of a center remote from other stereocenters. ${ }^{5,12}$ Our current hypothesis is that the MPVO reduction gives diastereoisomer D2 as the kinetic product when IPA is in vast excess (suppressing equilibration), but the "scrambling" reaction (with oxidation via an Oppenauer-type process) does indeed tend toward a thermodynamic equilibrium with diastereoisomer D1 in excess. However, this has not been unambiguously confirmed.

Reductions Using $\mathrm{Al}(\mathrm{iBu})_{3}$ as Reductant. Triisobutylaluminum (commonly abbreviated as TiBA) is most commonly encountered in the recent scientific literature as a polymerization cocatalyst or reagent for aluminum deposition in electronic applications. Nevertheless, it is also an effective reducing agent for aldehydes and ketones. While the neat liquid is pyrophoric, solutions in hexanes and toluene are both readily handled and widely available. Both the mechanism of reduction (a 6-membered cyclic transition state, involving ketone coordination to aluminum) and the steric demands using TiBA are very similar to the MPVO reaction. ${ }^{11,15}$ The key differences are that TiBA reduction is essentially irreversible and that no ketone byproduct is formed, features which we expected would help overcome the low conversions observed with $\mathrm{Al}(\mathrm{O} i \mathrm{Pr})_{3}$ reductions at practical concentrations. However, the reduction product (the aluminate formed from the 
Table 4. Reductions of Ketone 4 Using $\mathrm{Al}(i \mathrm{Bu})_{3}{ }^{a}$

\begin{tabular}{|c|c|c|c|}
\hline \multirow[b]{2}{*}{ entry } & \multirow[b]{2}{*}{ conditions } & \multicolumn{2}{|c|}{$\mathrm{D} 1 / \mathrm{D} 2$ ratio $^{b}$ (area\% conversion) } \\
\hline & & $2 \mathrm{~h}$ & $+72 \mathrm{~h}$ \\
\hline $8 \mathrm{~A}$ & 1 equiv of $\mathrm{Al}(\mathrm{iBu})_{3}(2 \mathrm{~min}$ addn $)$, TOL $(25 \mathrm{~mL} / \mathrm{g}), 5{ }^{\circ} \mathrm{C}, 30 \mathrm{~min}$, then $\mathrm{rt}$ & $8: 92(>99 \%)$ & n.a. \\
\hline $8 B$ & 1 equiv of $\mathrm{Al}(\mathrm{iBu})_{3}(30 \mathrm{~min}$ addn $)$, TOL $(25 \mathrm{~mL} / \mathrm{g}),-10$ to $0{ }^{\circ} \mathrm{C}, 2 \mathrm{~h}$, then $\mathrm{rt}$ & $6: 94(92 \%)$ & n.c. \\
\hline $8 \mathrm{C}$ & 1 equiv of $\mathrm{Al}(\mathrm{iBu})_{3}(2 \mathrm{~min}$ addn $)$, TOL $(25 \mathrm{~mL} / \mathrm{g}),-10$ to $0{ }^{\circ} \mathrm{C}, 2 \mathrm{~h}, 0.5$ equiv of 4 added, then $\mathrm{rt}$ & $7: 93(97 \%)$ & $13: 87(25 \%)$ \\
\hline $8 \mathrm{D}$ & 2 equiv of $\mathrm{Al}(\mathrm{iBu})_{3}(30 \mathrm{~min}$ addn $)$, TOL $(25 \mathrm{~mL} / \mathrm{g}),-10$ to $0{ }^{\circ} \mathrm{C}, 2 \mathrm{~h}$, then $\mathrm{rt}$ & $11: 89(>99 \%)$ & n.c. \\
\hline $9 \mathrm{~A}$ & 1 equiv of $\mathrm{Al}(i \mathrm{Bu})_{3}(30 \mathrm{~min}$ addn $), \mathrm{DCM}(25 \mathrm{~mL} / \mathrm{g})$ & $13: 87(>99 \%)$ & n.c. \\
\hline $9 \mathrm{~B}$ & 1 equiv of $\mathrm{Al}(i \mathrm{Bu})_{3}(30 \mathrm{~min}$ addn $)$, THF $(25 \mathrm{~mL} / \mathrm{g})$ & $<1 \%$ & n.a. \\
\hline $10 \mathrm{~A}$ & 1 equiv of $\mathrm{Al}(i \mathrm{Bu})_{3}(30 \mathrm{~min}$ addn $)$, TOL $(25 \mathrm{~mL} / \mathrm{g}),-78{ }^{\circ} \mathrm{C}$ to $\mathrm{rt}$, overnight & $6: 94(>99 \%)$ & n.a. \\
\hline 10B & 1 equiv of $\mathrm{Al}(i \mathrm{Bu})_{3}(30 \mathrm{~min}$ addn $)$, TOL $(12 \mathrm{~mL} / \mathrm{g}),-10$ to $0{ }^{\circ} \mathrm{C}$, then $\mathrm{rt}$ & $7: 93(>99 \%)$ & n.a. \\
\hline $10 \mathrm{C}$ & 1 equiv of $\mathrm{Al}(i \mathrm{Bu})_{3}(30 \mathrm{~min}$ addn $)$, TOL $(50 \mathrm{~mL} / \mathrm{g}),-10$ to $0{ }^{\circ} \mathrm{C}$, then $\mathrm{rt}$ & $7: 93(>99 \%)$ & n.a. \\
\hline $10 \mathrm{D}$ & 1 equiv of $\mathrm{Al}(i \mathrm{Bu})_{3}(60 \mathrm{~min}$ addn $)$, TOL $(12 \mathrm{~mL} / \mathrm{g}),-10$ to $0{ }^{\circ} \mathrm{C}$, then $\mathrm{rt}$ & $7: 93(>99 \%)$ & n.a. \\
\hline
\end{tabular}

${ }^{a}$ Conditions: see table. ${ }^{b}$ Ratio measured from Me ester peaks; TOL = toluene; n.a. = not applicable (reaction quenched at $2 \mathrm{~h}$ ); n.c. $=$ no change. Scale: $1 \mathrm{mmol}$ ketone 4 except for entry $10 \mathrm{C}(0.5 \mathrm{mmol})$ and entry $10 \mathrm{D}(20 \mathrm{mmol})$.

Scheme 4. Reduction of Ketone 4 Using TiBA on $100 \mathrm{~g}$ Scale
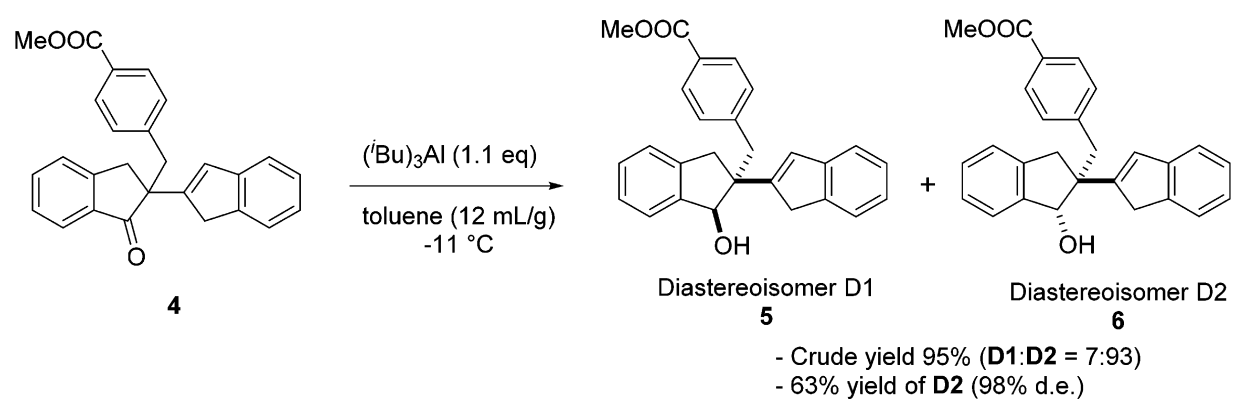

alkoxide after ketone reduction) can itself undergo equilibration via a MPVO-type mechanism if unreacted ketone is also present. ${ }^{16}$ When applied to our system, essentially complete conversion and a promising D1/D2 ratio (8:92) were achieved (Table 4, entry 8A), also supporting our hypothesis that diastereoisomer D2 is the kinetic product with reductions which proceed through a MPVO-type transition state. Based on the apparent efficiency and clean HPLC profile of this reaction, this route was explored further (Table 4, entries 8B-D). Each reaction was examined after $2 \mathrm{~h}$, and after extended stirring at $\mathrm{rt}$ to determine whether degradation or equilibration would occur. Overall, the reaction appeared robust. Lower temperature and slow reagent addition resulted in only small improvements to d.e. (entry $8 \mathrm{~B}$ ). While spiking of extra ketone into the reaction mixture (entry $8 \mathrm{C}$ ) led to slight erosion of d.e. (presumably via a slow MPVO-type equilibration), mixtures without significant ketone present showed no changes with time. Excess reagent (entry 8D) lead to no significant side products, although in this case the D1/D2 ratio (11:89) was slightly less favorable. When dichloromethane (DCM) was used as a solvent (entry 9A), the diastereoselectivity proved to be slightly poorer. Rather surprisingly, no conversion was observed in THF (entry 9B); use of a coordinating solvent in this case may have disrupted the coordination between the ketone and the reagent required for reaction. Returning to toluene as solvent (entries 10A-D), reactions proved largely insensitive to both concentration and temperature; the slight increase in d.r. resulting from a much lower reaction temperature did not warrant the use of cryogenic cooling. With entry 10B chosen as the most suitable for scaling up, entry 10D was performed on a $20 \mathrm{mmol}$ scale. The crude HPLC profile and product ratios were consistent as on a small scale, and a crude yield of $94 \%$ was obtained after workup.
To test the scalability of the process further, a reaction at 100 $\mathrm{g}$ scale was successfully conducted under similar conditions to those in entry 10B (Scheme 4). The diastereoselectivity of the reaction proved unaffected by scale. Following isolation and an unoptimized trituration purification, the $100 \mathrm{~g}$ reaction gave a $63 \%$ isolated yield of desired isomer D2 (98\% d.e.). A detailed reaction procedure and analytical results are given in the Experimental Section.

Phase Transfer Catalyst (PTC)-Promoted Alkylation of Ketone 3. Phase transfer catalysis has long been recognized as a powerful tool in both industrial and academic settings. The oft-quoted advantages include simple experimental operations (typically without exclusion of air or moisture), mild reaction conditions, the low cost of common reagents and catalysts, and the amenability to large scale process chemistry. ${ }^{17}$ In our original synthetic route, the quaternary center was introduced in a $\mathrm{KO} t \mathrm{Bu}$-promoted alkylation in $\mathrm{tBuOH} /$ diethyl ether, and using methyl(4-bromomethyl)benzoate as an electrophile. ${ }^{2}$ It was believed that this might readily be substituted by an achiral PTC process, using cheaper and less sensitive reagents, and potentially extended in future to an asymmetric process. In the current study, a short-proof-of-concept investigation was carried out using an achiral PTC. Given the potential instability of the methyl ester functionality in methyl(4-bromomethyl)benzoate under typical phase-transfer conditions, a more robust ester was chosen to simplify testing. tert-Butyl(4-bromomethyl)benzoate was prepared from 4-(bromomethyl)benzoic acid according to the literature method using tert-butyl-2,2,2trichloroacetimidate (TBTA) in a mixture of cyclohexane/ $\mathrm{DCM} / \mathrm{THF}$ at $\mathrm{rt}^{18}$ This alkylating agent was used in PTCpromoted alkylations of ketone 3 to afford keto $t \mathrm{Bu}$-ester $\mathbf{1 2}$ (Figure 1). Standard conditions were chosen, using $25 \%$ aq. $\mathrm{NaOH} /$ toluene (1:5) and tetrabutylammonium iodide (TBAI) 


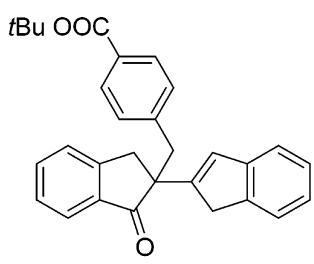

12

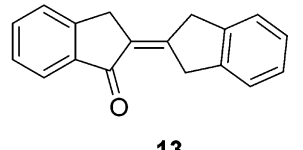

13

Figure 1. Molecular structures of keto $t$ Bu-ester 12 and the unsaturated ketone 13.

as the catalyst. Control reactions, without either ketone 3 or the alkylating agent, were also carried out. Initially, no PTC was added. HPLC analysis after $1 \mathrm{~h}$ of vigorous stirring showed neither significant degradation nor any uncatalyzed alkylation.

Following addition of the PTC, the HPLC profile for the reaction containing both ketone 3 and alkylating agent showed rapid and clean conversion to the desired alkylation product $\mathbf{1 2}$. The reaction was complete in under $3 \mathrm{~h}$ at ambient temperature, while extended stirring had no effect on HPLC profile. NMR spectra and HPLC chromatograms are given in the Supporting Information (Figures S7-S9). While the control reaction without ketone 3 showed no degradation of the alkylating agent after $16 \mathrm{~h}$, the reaction without alkylating agent resulted in partial degradation of ketone 3 , but the rate of decomposition was sufficiently slow not to be a concern under normal conditions. Among other species, the unsaturated ketone 13 resulting from methanol elimination from 3 was identified in the mixture. Although 13 is a potential intermediate in the desired alkylation process, the species was not observed in PTC- or KOtBu-promoted reactions, indicating that, if formed, it is rapidly consumed in the presence of the electrophile.

\section{CONCLUSION}

While investigation of the diastereoselective reduction of keto Me-ester 4 using borohydride reagents failed to improve the medchem route, exploration of Meerwein-Ponndorf-Verley systems was more promising, affording the desired product in good diastereoselectivity. Further investigations using the related, and yet much less common, TiBA were more successful, leading to a robust, selective, and scalable process and insights into the kinetic vs thermodynamic products in our system. This diastereoselective reduction method was successfully employed on multikilo scale in a GMP environment, achieving up to $70 \%$ yield and $>98 \%$ d.e. and purity (by area $\%$ ). Furthermore, the adoption of this step contributed toward a $20 \%$ overall cost reduction of the manufacturing of PH46A. The GMP campaign will be described in detail in a separate article.

Progress was also made toward replacing the original $\mathrm{KO} t \mathrm{Bu}-$ promoted alkylation of $\mathbf{3}$ with a cost-effective, simpler process using phase transfer catalysis. The reaction using a standard achiral quaternary ammonium catalyst proved effective under very simple conditions, though given time constraints this was not scaled-up. Extension to an enantioselective variant is currently under exploration in our laboratory.

\section{EXPERIMENTAL SECTION}

All solvents (as anhydrous, HPLC, or general process grades) and reagents were purchased commercially and used as received. Air-sensitive solutions in septum-sealed bottles were dispensed under a balloon of nitrogen and capped immediately after use. NMR spectra were recorded using a Varian $400 \mathrm{MHz}$ system and processed using MestreNova software. Chemical shifts are quoted in ppm relative to tetramethylsilane as the internal standard. Reversed phase (achiral) HPLC analyses were conducted on an Agilent 1200 LC with a quaternary pump, column oven, and diode array detector with data processing using Chemstation software. Chromatographic conditions: Zorbax C18 XDB column $(150 \mathrm{~mm} \times 4.6 \mathrm{~mm})$ $5 \mu \mathrm{m}$; eluent A (water + 0.1\% TFA v/v): B (MeOH) 20:80; 1.0 $\mathrm{mL} / \mathrm{min}$; column oven $40{ }^{\circ} \mathrm{C}$; run time $15 \mathrm{~min}$; injection volume $5 \mu \mathrm{L}$; reference standard concentration: $1 \mathrm{mg} / \mathrm{mL}$ in diluent. Sample preparation from PTC alkylations: reaction mixture sample $(2.5 \mu \mathrm{L})$ was diluted with IPA $(1 \mathrm{~mL})$. Sample preparation from reductions: reaction mixture sample $(5 \mu \mathrm{L})$ was quenched with $3 \mathrm{M}$ aq. $\mathrm{HCl}(100 \mu \mathrm{L})$ which was then diluted with IPA $(1 \mathrm{~mL})$. For diastereoselective reductions, $\mathrm{Al}(\mathrm{O} i \mathrm{Pr})_{3}, \mathrm{Nd}(\mathrm{O} i \mathrm{Pr})_{3}$, and $\mathrm{LiBH}_{4}$ were opened and stored in a $\mathrm{N}_{2}$ glovebag (no active removal of moisture or oxygen other than gentle $\mathrm{N}_{2}$ purging) for the duration of the project.

Representative Procedure for MPVO Reduction of Methyl Ester 4 (Entry 4B). To a solution of keto Me-ester 4 $(98 \mathrm{mg}, 0.25 \mathrm{mmol})$ in IPA $(15 \mathrm{~mL})$ was added $\mathrm{Al}(\mathrm{OiPr})_{3}(204$ $\mathrm{mg}, 0.5 \mathrm{mmol})$ in a single portion at rt. The reaction mixture was purged with $\mathrm{N}_{2}$ and heated to gentle reflux. Conversion was determined by reversed phase HPLC. When the reaction was complete, the mixture was acidified using $1 \mathrm{M}$ aq. $\mathrm{HCl}$ and extracted with EtOAc. The organic phase was washed with brine, dried over $\mathrm{MgSO}_{4}$, filtered, and concentrated to afford the crude mixture of $\mathbf{9 / 1 0}$ as a hard foam.

MPVO "Scrambling" of Diastereoisomeric Mixture 5/6 (Entry 7). A mixture of 5 and 6 (D1/D2, 3:2, $396 \mathrm{mg}, 1.0$ $\mathrm{mmol})$ was mixed in dry toluene $(10 \mathrm{~mL})$ in a flame-dried reaction tube. Toluene was removed under reduced pressure. The procedure was repeated with a second portion of dry toluene $(10 \mathrm{~mL})$. The residue was taken up in dry toluene (10 $\mathrm{mL})$, and $\mathrm{Nd}(\mathrm{OiPr})_{3}(63 \mathrm{mg}, 0.2 \mathrm{mmol})$ was added. The tube was purged with $\mathrm{N}_{2}$ and placed in an aluminum heating block (block temperature $55^{\circ} \mathrm{C}$ ). Dry acetone $(74 \mu \mathrm{L}, 1 \mathrm{mmol})$ was then added, resulting in a change of color from blue to yellow. Conversion was determined by HPLC. The area ratio after 2.5 $\mathrm{h}$ at $55{ }^{\circ} \mathrm{C}$ was $(\mathrm{D} 1 / \mathrm{D} 2 / 11)$ 22:3:75. The reaction products were not isolated.

$100 \mathrm{~g}$ Scale-up Reduction of Keto Me-ester 4. Toluene $(1.2 \mathrm{~L})$ and keto Me-ester $4(99.1 \mathrm{~g}, 251 \mathrm{mmol})$ were charged to the vessel, and the mixture was stirred $(250 \mathrm{rpm})$ for $30 \mathrm{~min}$ while the vessel atmosphere was purged with $\mathrm{N}_{2}$. The mixture was cooled to an internal temperature of $-12{ }^{\circ} \mathrm{C}$. A solution of $\mathrm{Al}(i \mathrm{Bu})_{3}(1.1 \mathrm{M}$ in toluene, $219 \mathrm{~g}, 288 \mathrm{mmol})$ was pumped into the vessel through PTFE tubing over $1 \mathrm{~h}$. The internal temperature rose and steadied at $-11{ }^{\circ} \mathrm{C}$. After addition, the reaction mixture was allowed to warm slowly with stirring for a period of $2 \mathrm{~h}$, reaching an internal temperature of $10{ }^{\circ} \mathrm{C}$. Addition of water $(100 \mathrm{~mL})$ resulted in a rise of the internal temperature to $28{ }^{\circ} \mathrm{C}$. Aq. $\mathrm{HCl}(1 \mathrm{M}, 0.6 \mathrm{~L})$ was added, accompanied by a slight further exotherm to $29{ }^{\circ} \mathrm{C}$. The aqueous layer was discarded, and the organic phase was washed further with aq. $\mathrm{HCl}(1 \mathrm{M}, 0.3 \mathrm{~L})$ and brine $(0.3 \mathrm{~L})$. The organics were dried over $\mathrm{MgSO}_{4}$, filtered, and concentrated under reduced pressure at $50{ }^{\circ} \mathrm{C}$ to afford crude 4 as a solid (95 g). The solid was triturated in MTBE ( $95 \mathrm{~mL}$ ) for $2 \mathrm{~h}$ and left to stand overnight at $5{ }^{\circ} \mathrm{C}$. HPLC analysis of the supernatant at this stage indicated a d.e. of $49 \%$. The solid was collected by filtration, washed with cold MTBE (95 mL in two portions), 


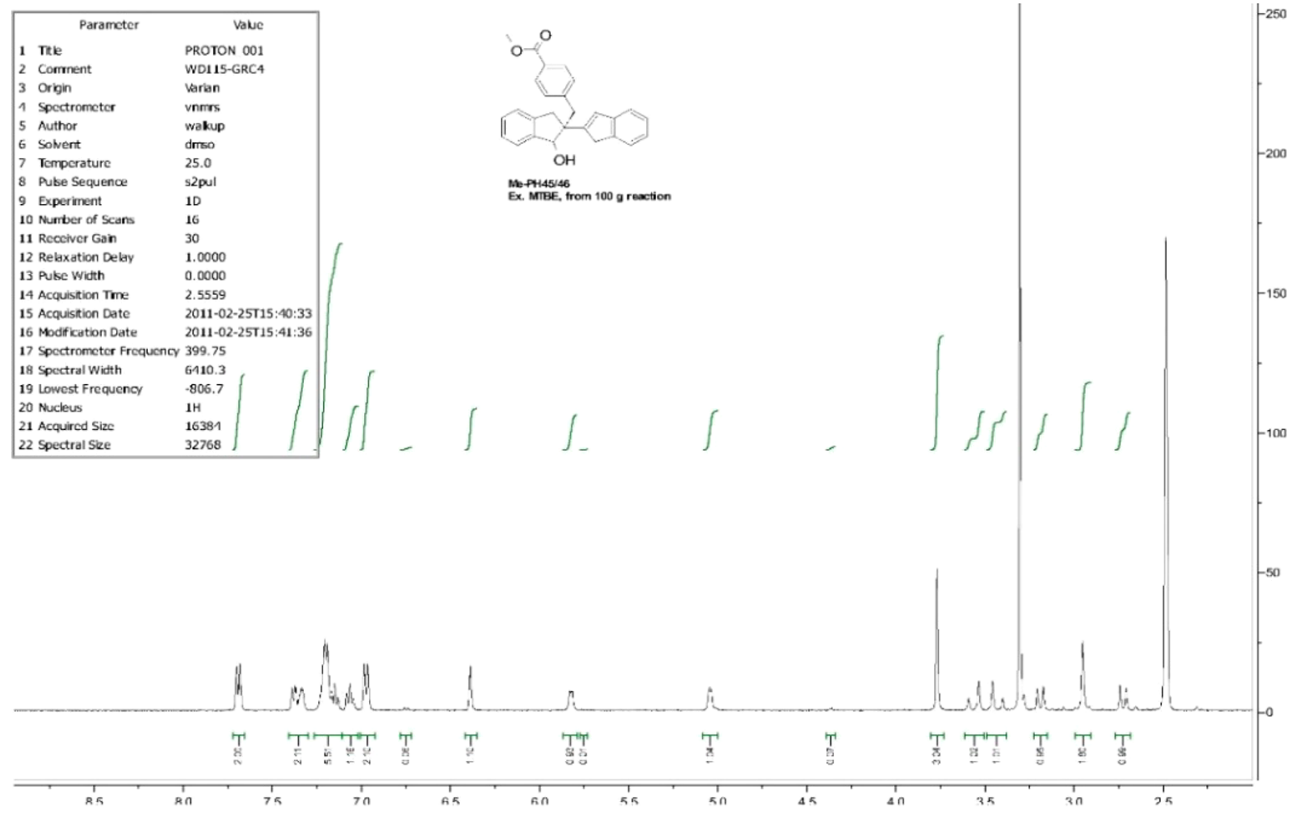

Figure 2. ${ }^{1} \mathrm{H}$ NMR spectrum of hydroxyl Me-ester 6.

and dried to afford diastereoisomer 6 (63 g, 63\%) with 95\% purity and $98 \%$ d.e. The ${ }^{1} \mathrm{H}$ NMR spectrum is given in Figure 2.

${ }^{1} \mathrm{H}$ NMR (400 MHz, dmso-d $\left.\mathrm{d}_{6}\right) \delta \mathrm{H}(\mathrm{ppm}): 7.70$ (d, $J=8.4$ $\mathrm{Hz}, 2 \mathrm{H}, \mathrm{Ar}-\mathrm{H}), 7.34-7.40$ (m, 2H, Ar-H), 7.14-7.25 (m, 5H, $\mathrm{Ar}-\mathrm{H}), 7.07(\mathrm{t}, J=14.4 \mathrm{~Hz}, 1 \mathrm{H}, \mathrm{Ar}-\mathrm{H}), 6.97(\mathrm{~d}, J=8.4 \mathrm{~Hz}$, $2 \mathrm{H}, \mathrm{Ar}-\mathrm{H}), 6.39(\mathrm{~s}, 1 \mathrm{H}, \mathrm{CH}=\mathrm{C}), 5.85(\mathrm{~d}, J=7.2 \mathrm{~Hz}, 1 \mathrm{H}$, $\mathrm{CHOH}), 5.06(\mathrm{~d}, J=6.8 \mathrm{~Hz}, 1 \mathrm{H}, \mathrm{CHOH}), 3.77\left(\mathrm{~s}, 3 \mathrm{H}, \mathrm{CH}_{3}\right)$, $3.56\left(\mathrm{~d}, J=23.2 \mathrm{~Hz}, 1 \mathrm{H}, \mathrm{CH}_{2}\right), 3.42\left(\mathrm{~d}, J=23.2 \mathrm{~Hz}, 1 \mathrm{H}, \mathrm{CH}_{2}\right)$, $3.20\left(\mathrm{~d}, J=13.6 \mathrm{~Hz}, 1 \mathrm{H}, \mathrm{CH}_{2}\right), 2.96\left(\mathrm{~s}, 2 \mathrm{H}, \mathrm{CH}_{2}\right), 2.73(\mathrm{~d}, J=$ $13.6 \mathrm{~Hz}, 1 \mathrm{H}, \mathrm{CH}_{2}$ ).

General Procedure for PTC Alkylation. Ketone 3 (69 $\mathrm{mg}, 0.25 \mathrm{mmol}$ ) and tert-butyl(4-bromomethyl)benzoate (68 $\mathrm{mg}, 0.25 \mathrm{mmol})$ were taken up in toluene $(2.5 \mathrm{~mL})$ and charged to a $20 \mathrm{~mm}$ diameter vial. TBAI $(5 \mathrm{mg})$ and $25 \%$ aq. $\mathrm{NaOH}(0.5 \mathrm{~mL})$ were added, and the mixture was stirred at $1500 \mathrm{rpm}$ overnight. The phases were separated, and the toluene phase was concentrated under reduced pressure to afford the crude product.

\section{ASSOCIATED CONTENT}

\section{S Supporting Information}

The Supporting Information is available free of charge on the ACS Publications website at DOI: 10.1021/acs.oprd.7b00258.

Details of experimental procedures for the synthesis of the reference molecules and their corresponding analytical data including NMR spectra and HPLC chromatograms (PDF)

\section{AUTHOR INFORMATION}

\section{Corresponding Author}

*E-mail: hsheridn@tcd.ie.

\section{ORCID}

Tao Zhang: 0000-0003-1079-5364

\section{Author Contributions}

"G.R.C., T.Z., and G.S. contributed equally to the manuscript. Notes

The authors declare no competing financial interest.

\section{ACKNOWLEDGMENTS}

This work was supported by The Wellcome Trust, Grant Reference No. 067033/Z/02/A, Enterprise Ireland, Celtic Catalysts Ltd and Trino Therapeutics Ltd. The authors would like to acknowledge the contributions of Dr. Jenny Cumming (née Rickerby; Celtic Catalysts) and Dr. Andy Baxter (ProPharma Partners Ltd) to this work.

\section{REFERENCES}

(1) Frampton, C.-S.; Zhang, T.; Scalabrino, G.; Frankish, N.; Sheridan, H. Acta Crystallogr., Sect. C: Cryst. Struct. Commun. 2012, 68, o323.

(2) Frankish, N.; Sheridan, H. J. Med. Chem. 2012, 55, 5497.

(3) Therapeutics, T. A study to assess the safety and tolerability of PH46A in healthy volunteers, to measure drug levels in these subjects and to determine the effect of food on the drug's absorption. BioMed Central: ISRCTN Registry, EudraCT: 2013-003717-17, 2014.

(4) Frankish, N.; Sheridan, H. Unpublished results on Stereochemistry; 2010.

(5) Klomp, D.; Djanashvili, K.; Svennum, N.-C.; Chantapariyavat, N.; Wong, C.-S.; Vilela, F.; Maschmeyer, T.; Peters, J.-A.; Hanefeld, U. Org. Biomol. Chem. 2005, 3, 483.

(6) Snyder, S.-E.; Shvets, A.-B.; Pirkle, W.-H. Helv. Chim. Acta 2002, $85,3605$.

(7) Makosza, M. Pure Appl. Chem. 2000, 72, 1399.

(8) Brown, H.-C. Organic Synthesis via Boranes; Wiley-Interscience: New York, 1975.

(9) Brown, H.-C.; Mead, E.-J.; Subba-Rao, B.-C. J. Am. Chem. Soc. $1955,77,6209$.

(10) Graves, C.-R.; Joseph-Campbell, E.; Nguyen, S.-T. Tetrahedron: Asymmetry 2005, 16, 3460.

(11) Cha, J.-S. Org. Process Res. Dev. 2006, 10, 1032.

(12) Klomp, D.; Maschmeyer, T.; Hanefeld, U.; Peters, J.-A. Chem. Eur. J. 2004, 10, 2088.

(13) Lee, J.; Ryu, T.; Park, S.; Lee, P.-H. J. Org. Chem. 2012, 77, 4821.

(14) Wang, Z. In Comprehensive Organic Name Reactions and Reagents; John Wiley \& Sons, Inc.: 2010.

(15) Winterfeldt, E. Synthesis 1975, 1975, 617.

(16) Haubenstock, H.; Davidson, E.-B. J. Org. Chem. 1963, 28, 2772.

(17) Ooi, T.; Maruoka, K. Angew. Chem., Int. Ed. 2007, 46, 4222. 
(18) Halbert, S.-M.; Michaud, E.; Thompson, S.-K.; Veber, D.-F.

Protease inhibitors, PCT US Appl. US20020049316, April 25, 2002. 